\title{
Study On Effect of Boron Carbide, Aluminium Oxide and Graphite On Dry Sliding Wear Behaviour of Aluminium Based Metal Matrix Composite at Different Temperature
}

\author{
Sharath B N, C V Venkatesh \\ Department of Mechanical Engineering, Malnad College of Engineering, Hassan, VTU, Belagavi, Karnataka, India \\ Corresponding author: Sharath B N (sbn@mcehassan.ac.in)
}

\begin{abstract}
The present research has been conducted to study the impact of boron carbide $\left(\mathrm{B}_{4} \mathrm{C}\right)$, aluminium oxide $\left(\mathrm{Al}_{2} \mathrm{O}_{3}\right)$ and graphite on Aluminium 2219 (A12219). According to current research, $\mathrm{B}_{4} \mathrm{C}$ and graphite material be a good substitute for Al2219.Reinforced composites and unreinforced Al2219 prepared by a stir casting process. A scanning electron microscope was used to analyze the reinforcement and distribution in the matrix and worn surface of the specimen. Exceptional wear resistance (30\%) exhibited by $\mathrm{B}_{4} \mathrm{C}$ and graphite-reinforced hybrid composite at 150 ${ }^{\circ} \mathrm{C}$ in contrast with the unreinforced $\mathrm{Al} 2219$. The $\mathrm{B}_{4} \mathrm{C}$ and $\mathrm{Gr}$ reinforcement particulate existence improves the strengthening kinetics in the matrix phase at $150^{\circ} \mathrm{C}$. The artificial neural network used to get the test significance, normalized factor importance and absolute relative error of less than $1 \%$.
\end{abstract}

Keywords: Artificial neural network, oxide layer, worn surface, metal matrix composites

\section{Introduction}

The virtue of enlightenment which we enjoy today, is essential due to the improved quality products obtained. Enhancement in the quality of goods can be achieved by a genuine design that considers the functional requirement and its manufacturing aspects. The design process should take proper care of the synthesis technique, which should be an ideal one ensuring the better product is being made available at an economical cost [1]. Furthermore, the productive manufacturing process is an imperative consideration to be accessible in modern industries. Also, the produced product has to competitively priced and should be functional concerning the environment and aesthetic appeal [2]. Aluminium (Al) alloys are of great importance for the transportation sector because of their high strength-tomass ratios. Still, adhesion is a typical hindrance in the forming and machining of these alloys [3]. AMMCs (Aluminium metal matrix composites) are better at replacing traditional aluminium alloy because of their characteristics [4]. AMMCs exhibit higher wear resistance than monolithic materials [5]. Ceramic reinforced composites are rapidly developing fields due to their progress in the aerospace, aircraft and automobile industries. The lower specific gravity of these materials makes their properties superior concerning mechanical and physical properties [6]. The intensive study into the fundamental properties of the composite materials by reinforcing ceramics to understand their nature, structural and physical properties. To obtain better properties of the material, constituting phases must be altered [7]. The inclusion of small quantities of strong hard

particles significantly increased stiffness, creep and wear resistance $[8,9]$. It is now well recognized that ceramic reinforcement dispersion in AMMCs contribute to substantial increases in rigidity and wear resistance [10]. There was a limit above which the addition of graphite(Gr) or $\mathrm{SiC}$ (Silicon carbide) was not favourable for the Al-Gr/Al-SiC composite [11]. Incorporating graphite as primary compliance improves the composites wear-resistance by creating a protective layer between the pin and the counter side and exceptionally influences wear resistance by adding alumina as secondary compliance [12]. Better hardness is exhibited when $\mathrm{Al}$ alloy reinforced with $\mathrm{Al}_{2} \mathrm{O}_{3}$ [13]. Many studies have concentrated on the manufacture of $\mathrm{SiC}, \mathrm{Al}_{2} \mathrm{O}_{3}$

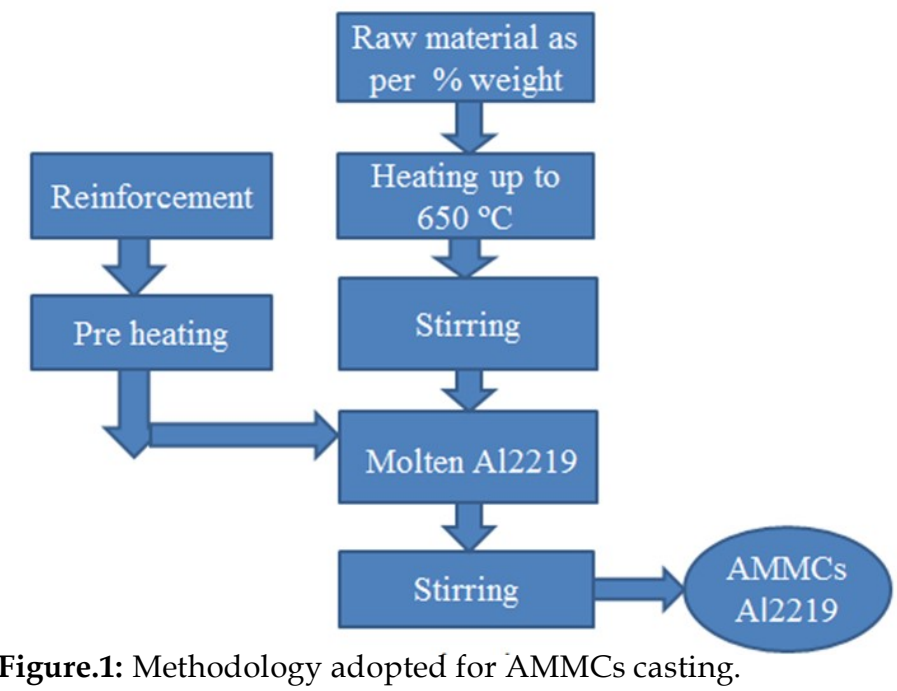

TRIBOLOGIA - Finnish Journal of Tribology 1-2 vol 38/2021 
Table 1: Materials used for the synthesis of composite

Materials Used for the synthesis of composite
Aluminium 2219
Magnesium as wettability agent
Boron carbide $\left(\mathrm{B}_{4} \mathrm{C}\right)$
Graphite
Aluminum oxide $\left(\mathrm{Al}_{2} \mathrm{O}_{3}\right)$
Hexa-chloroethane to remove gas from the molten metal

(aluminium oxide) and $\mathrm{TiB}_{2}$ (Titanium diboride) as refinement material. But there is limited use of the $\mathrm{B}_{4} \mathrm{C}$ particles [14]. Silicon (Si) was the well known alloying material found in most aluminium casting alloys. Three main types of Al-Si alloy systems are Hypereutectic (14-25 wt \% Si), Eutectic (12-13 wt \% Si), Hypoeutectic (<12 wt \% Si) [15]. To maximize the engine block's efficiency, $\mathrm{Cu}$ (copper) and $\mathrm{Mg}$ (magnesium) were added into $\mathrm{Al}$ alloys that work at a wide variety of temperatures and stresses [16]. Cu (0.2-2.5 wt \%) influences the strength and hardness of aluminium alloy at room and elevated temperature [17]. To avoid clustering of graphite particles, $\mathrm{Mg}$ was added into the matrix; thus, the physical and mechanical properties of the aluminium matrix enhanced [18, 19]. The Artificial Neural Network ( ANN) was an iterative technique that would be the most popular algorithm to several metallurgy investigators [33]. This is a statistical method used to solve various technical and research problems [34,35].

Literature shows relatively little details on advances in the $2 X X X$ aluminium alloy series reinforced with boron carbide-graphite, $\mathrm{Al}_{2} \mathrm{O}_{3}$-graphite particles, and very little data is available on dry sliding wear properties at high temperature. Keeping in view of the literature survey, current work was aimed at developing new hybrid composites. Therefore this study attempted to investigate the high -temperature dry sliding wear behaviour of new ( $\mathrm{Al}-0.02$ $\% \mathrm{Mg}-0.2 \% \mathrm{Si}-6.8 \% \mathrm{Cu}-0.25 \% \mathrm{Zr}$ ) heat resistant aluminium alloy 2219 and strengthened by ceramic particulates $\mathrm{Al}_{2} \mathrm{O}_{3}, \mathrm{~B}_{4} \mathrm{C}$ and graphite. New AMMCs was manufactured by using a stir casting process.

\section{Experimental procedure}

\subsection{Materials and Synthesis of Composite}

The stir casting route has done the solidification process. The methodology adopted for AMMCs casting, as shown in figure.1 and the material used to synthesis AMMCs, are listed in table 1, weighed commercially available Al2219 was melted at $650{ }^{\circ} \mathrm{C}$ in a pottery-graphite crucible, meanwhile the magnesium lump of $3 \mathrm{wt}$. \% added to the same for further enhancement of wettability.
Table 3. Material composition in percentage [15]

\begin{tabular}{ccccc}
\hline Sample & Al2219 & $\begin{array}{c}\text { B4C } \\
\text { wt. \% }\end{array}$ & $\begin{array}{c}\text { Al2O3 } \\
\text { wt. \% }\end{array}$ & Graphite, wt. \% \\
\hline A & 100 & - & - & - \\
A1 & 90 & - & 5 & 5 \\
A2 & 90 & 5 & - & 5 \\
\hline
\end{tabular}

Once the collected ingot in the crucible reaches a liquid state over time, a certain slag was collected at the top and removed to avoid casting defects. After that, preheated commercially available weighed $\mathrm{Al}_{2} \mathrm{O}_{3}(30 \mu \mathrm{m})$ was added as reinforcement into the crucible. The desired times of the elapsed stirring (speed of $150 \mathrm{rpm}$ ) occur in the crucible to give a proper homogeneous mixture. Preheated graphite was added into the crucible as a secondary reinforcement, and the same procedure was adopted to get a hybrid homogenous mixture [20]. The mixed molten metal slurry is poured into a split type preheated permanent graphite mould. The hybrid composites have been synthesized by reinforcing wt.\% of $\mathrm{Al}_{2} \mathrm{O}_{3}$, graphite, $\mathrm{B}_{4} \mathrm{C}$ powder $(30 \mu \mathrm{m})$. Constituents of $\mathrm{Al} 2219$ is shown in table 2.

\subsection{Microstructure and XRD}

The Microstructure and worn surfaces of the tests specimens were studied using a scanning electron microscope (SEM) (high-performance Quanta 200 FEG-SEM) magnification range: $12 x$ to $1,00,000$. Backscatter Diffraction was used to capture the image. Captured SEM images help to see the microstructure and worn surface of the test specimens. The diffractometer equipped with $\mathrm{CuK}$ radiation $\mathrm{k}^{1 / 41: 54}$ _ AP. During XRD examination, an angle of 10-80 ${ }^{\circ}$ for the diffraction angle (20) was maintained [24].

\subsection{Hardness test}

The hardness of a specimen was measured (Model: PHB-3000) by pressing chromium-steel or tungsten-carbide against the surface of a test specimen. Samples were prepared as per ASTM E-10 standards (IS 1500 (II): 2013, ISO

Table 4. Factors and their levels used in the study.

\begin{tabular}{cccc}
\hline Factors & \multicolumn{3}{c}{ Levels } \\
\cline { 2 - 4 } & 1 & 2 & 3 \\
\hline Load, $\mathrm{N}$ & 20 & 30 & 40 \\
Speed, $\mathrm{m} / \mathrm{s}$ & 1.25 & 2.5 & 3.75 \\
Sliding distance, $\mathrm{m}$ & 400 & 600 & 800 \\
Temperature, ${ }^{\circ} \mathrm{C}$ & 50 & 100 & 150 \\
\hline
\end{tabular}

Table 2: Constituents of Al2219 [21]

\begin{tabular}{cccccccccc}
\hline Constituents & $\mathrm{Si}$ & $\mathrm{Mg}$ & $\mathrm{Zr}$ & $\mathrm{Cu}$ & $\mathrm{Fe}$ & $\mathrm{Mn}$ & $\mathrm{Ti}$ & $\mathrm{V}$ & $\mathrm{Zn}$ \\
\hline Weight \% & 0.2 & 0.02 & $0.1-0.25$ & $5.8-6.8$ & 0.3 & 0.02 & 0.02 & 0.05 & 0.1 \\
\hline
\end{tabular}


Table 5. Layout plan and experimental results.

\begin{tabular}{|c|c|c|c|c|c|c|c|}
\hline \multirow{3}{*}{$\begin{array}{l}\text { Exp. } \\
\text { runs }\end{array}$} & \multirow{3}{*}{$\begin{array}{l}\text { Load } \\
(\mathrm{N})\end{array}$} & \multirow{3}{*}{$\begin{array}{l}\text { Speed } \\
(\mathrm{m} / \mathrm{s})\end{array}$} & \multirow{3}{*}{$\begin{array}{c}\text { Distance } \\
\text { (m) }\end{array}$} & \multirow{3}{*}{$\begin{array}{c}\text { Ttemperature } \\
\left({ }^{\circ} \mathrm{C}\right)\end{array}$} & \multicolumn{3}{|c|}{ Wear rate $\mathrm{mm} / \mathrm{m} 3$} \\
\hline & & & & & Sample & Sample & Sample \\
\hline & & & & & $\mathrm{A} 2$ & A1 & $\mathrm{A}$ \\
\hline 1 & 20 & 1.25 & 400 & 50 & 0.9247 & 1.0471 & 1.1734 \\
\hline 2 & 20 & 1.25 & 600 & 100 & 0.5724 & 0.6437 & 0.7356 \\
\hline 3 & 20 & 1.25 & 800 & 150 & 0.2807 & 0.3754 & 0.4376 \\
\hline 4 & 20 & 2.51 & 400 & 100 & 1.0898 & 1.13456 & 1. 2045 \\
\hline 5 & 20 & 2.51 & 600 & 150 & 0.9467 & 1.0567 & 1.1435 \\
\hline 6 & 20 & 2.51 & 800 & 50 & 1.1063 & 1.2560 & 1.3436 \\
\hline 7 & 20 & 3.76 & 400 & 150 & 0.9347 & 1.1397 & 1.2876 \\
\hline 8 & 20 & 3.76 & 600 & 50 & 1.343 & 1.4945 & 1.5478 \\
\hline 9 & 20 & 3.76 & 800 & 100 & 1.1393 & 1. 2675 & 1.3956 \\
\hline 10 & 30 & 1.25 & 400 & 100 & 1.0127 & 1.1731 & 1.2674 \\
\hline 11 & 30 & 1.25 & 600 & 150 & 0.77058 & 0.9675 & 1.0345 \\
\hline 12 & 30 & 1.25 & 800 & 50 & 1.0401 & 1.1413 & 1.2876 \\
\hline 13 & 30 & 2.51 & 400 & 150 & 1.0568 & 1.1564 & 1.2543 \\
\hline 14 & 30 & 2.51 & 600 & 50 & 1.4971 & 1.5341 & 1.6341 \\
\hline 15 & 30 & 2.51 & 800 & 100 & 1.2634 & 1.3436 & 1.4765 \\
\hline 16 & 30 & 3.76 & 400 & 50 & 1.7833 & 1.8331 & 1.9761 \\
\hline 17 & 30 & 3.76 & 600 & 100 & 1.2549 & 1.3564 & 1.4871 \\
\hline 18 & 30 & 3.76 & 800 & 150 & 1.0726 & 1.1543 & 1.2358 \\
\hline 19 & 40 & 1.25 & 400 & 150 & 1.1889 & 1.2987 & 1.3456 \\
\hline 20 & 40 & 1.25 & 600 & 50 & 1.2989 & 1.3659 & 1.4567 \\
\hline 21 & 40 & 1.25 & 800 & 100 & 1.10634 & 1.2568 & 1.3456 \\
\hline 22 & 40 & 2.51 & 400 & 50 & 1.9154 & 2.0145 & 2.1678 \\
\hline 23 & 40 & 2.51 & 600 & 100 & 1.4321 & 1.5678 & 1.6789 \\
\hline 24 & 40 & 2.51 & 800 & 150 & 1.1286 & 1. 2674 & 1.3456 \\
\hline 25 & 40 & 3.76 & 400 & 100 & 1.4318 & 1.5678 & 1.6398 \\
\hline 26 & 40 & 3.76 & 600 & 150 & 1.343 & 1.4567 & 1.5768 \\
\hline 27 & 40 & 3.76 & 800 & 50 & 1.5791 & 1.6578 & 1.7658 \\
\hline
\end{tabular}

6506: 2005). The hardness number was reported from digital testers at the load of $240 \mathrm{kgf}$ and dwell time of $30 \mathrm{sec}$ [25].

\subsection{Wear test}

By conducting wear tests, it helps to discern wear properties. Measurable wear depends on the measuring method. In general, two ways are accessible to measure wear rate, such as weight loss and volume loss, out of which mass-loss method is the amenable method. In this method, weight loss must not be varied with condensed moisture and other foreign contaminants such as oil, dust etc. On the other hand, volume loss is also the best method to measure wear, but it is a more sensitive method [22]. Pin-on-disc (Pin heating-wear and friction monitor TR-20-PHM 400) testing apparatus was used to discern dry sliding wear behaviour of Al2219 and AMMCs at different temperature. As per the G99 standard [23], $10 \mathrm{~mm}$ diameter round pin of the AMMCs were made to slide against the rotating steel 


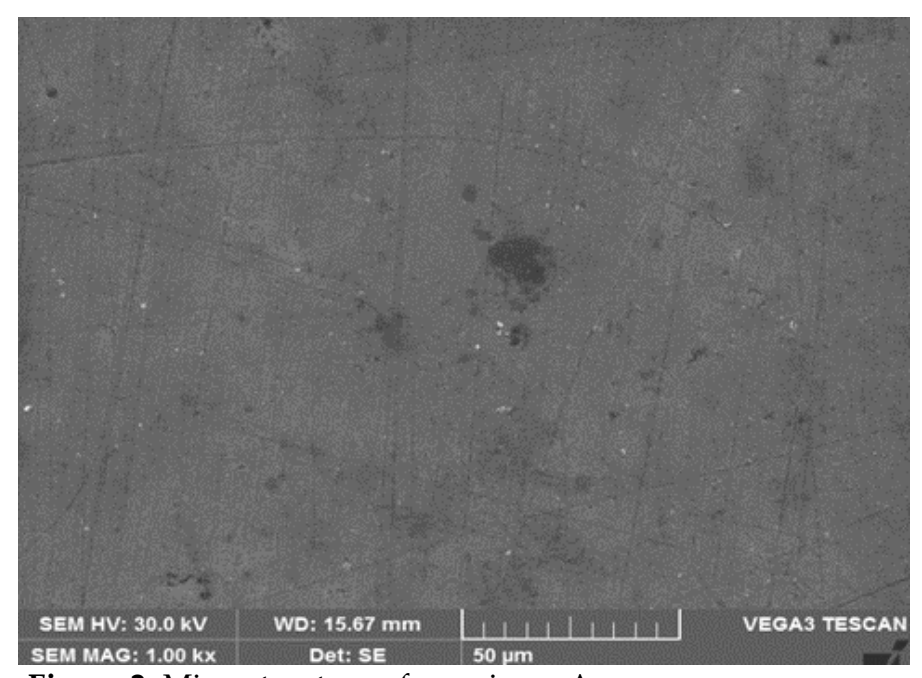

Figure.2: Microstructure of specimen A

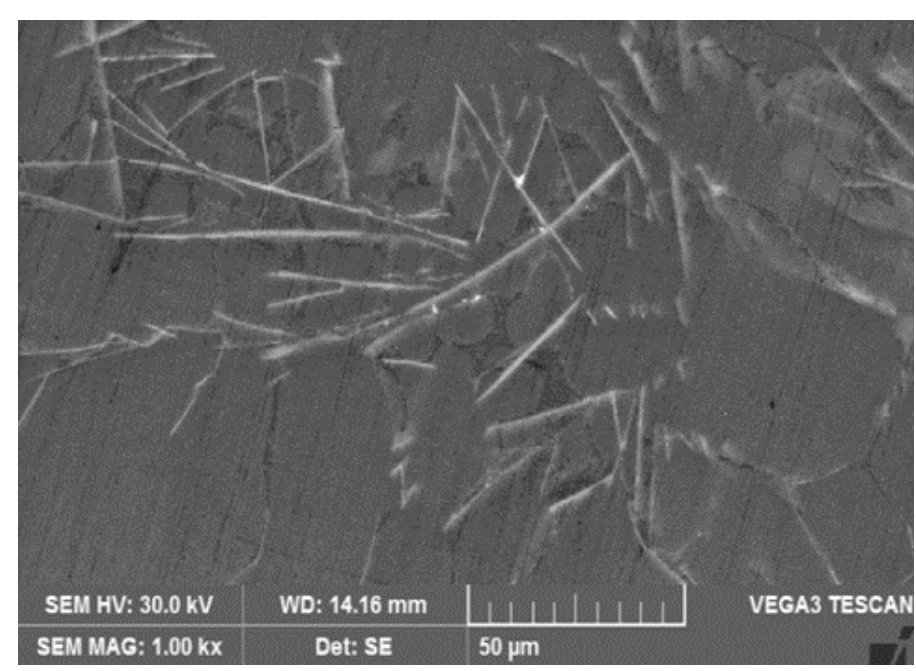

Figure.3: Microstructure of specimen $\mathrm{A}_{1}$

disc (steel EN - 32 ) at different temperatures such as $50^{\circ} \mathrm{C}$, $100{ }^{\circ} \mathrm{C}$ and $150{ }^{\circ} \mathrm{C}$ [21]. While conducting the test, acetone was used to clean the specimen and disc. Here, acetone acts as a chemical agent to protect the surface of the test pin and steel disc from the atmosphere. Before and after, the test specimen's mass was recorded using an Electronic balance weigher ( $0.0001 \mathrm{~g}$ resolution). Table 4 shows wear test parameters.

\subsection{Design of Experiments}

Taguchi's L27 orthogonal array is used to design the experiments. The experimental layout plan and measured average responses are presented in table 5. Load, Speed, Distance, and temperature are taken as input parameters, whereas wear rate is the responses.

\section{Result and discussions}

\subsection{Microstructural Examination}

XRD pattern and SEM of the matrix alloy and hybrid composites for the corresponding composition is shown in

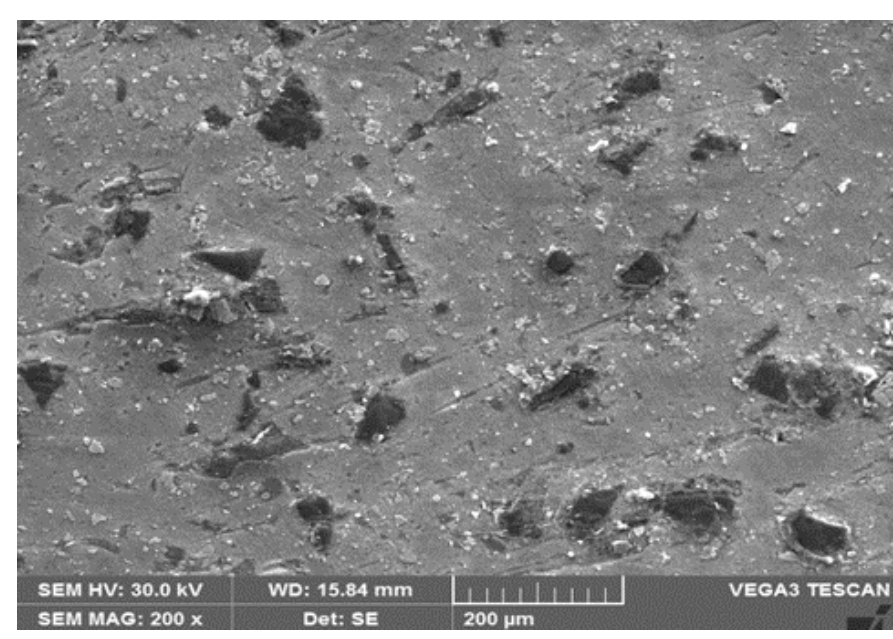

Figure.4: Microstructure of specimen $\mathrm{A}_{2}$

figure (2-7). The results obtained from XRD analysis revealed that the firm peaks belong to the parent material, i.e., aluminium. The smaller peaks also indicate $\mathrm{Cu}, \mathrm{Mg}$ and $\mathrm{B}_{4} \mathrm{C}$ in the hybrid composites(A2). $\mathrm{Al}_{2} \mathrm{O}_{3}$ also presents as seen in smaller peak (A1).

The microstructure of this hybrid composite shown by SEM images Fig.2-4. The bright area indicates oxides and is evident enough to show the discrete particles, and no appreciable accumulation was observed in fig. 3. On the other hands, the intermetallic $\mathrm{Al}_{3} \mathrm{Mg}_{2}$ seems like a flake shape and are small. A dark spot noticed, and its indicate porosity in the hybrid composite. Fig .4 shows the distribution of $\mathrm{B}_{4} \mathrm{C}$ and graphite [similar result observed by Kumar et al. and sing et al.]

\subsection{Hardness test}

Figure. 8 illustrates the hardness values of the test samples. It is confirmed that sample A2 exhibits higher hardness than $\mathrm{A} 1$ and $\mathrm{A}$. Due to the existence of $\mathrm{B}_{4} \mathrm{C}$ and graphite, the hardness of the composites increased. $\mathrm{B}_{4} \mathrm{C}$ was the third hardest material, and it acts as a barrier to dislocation; meanwhile, the strengthening effect of graphite also influences the hardness of the composite.

\subsection{Wear Analysis at Different Temperatures}

Microscope images help visualize the typically worn surface of a pin due to the adhesion of wear debris wear tracks formed [Wang et al. Observed similar result] on the sample, as clearly seen in fig 11 . Due to the formation of the oxide transferred layer, the worn surface is enfolded. It minimizes the direct metal to metal contacts between the interface, thereby minimizing weight loss. However, the tribo-layer is not a permanent layer at higher loads; this tribo-layer gets ruptured and tends to increase the wear rate, as shown in fig.11. The microstructure of the new alloy predominantly comprised of $\mathrm{Al}-\mathrm{Cu}-\mathrm{Mg}$ and matrix phase was analyzed and confirmed as an incoherent interface with a matrix that also influences the wear rate [similar result observed by Rajaram et al.]. Comparing worn surfaces of $\mathrm{Al}_{2} \mathrm{O}_{3}$ reinforced composite, the $\mathrm{Al} 2219$ 


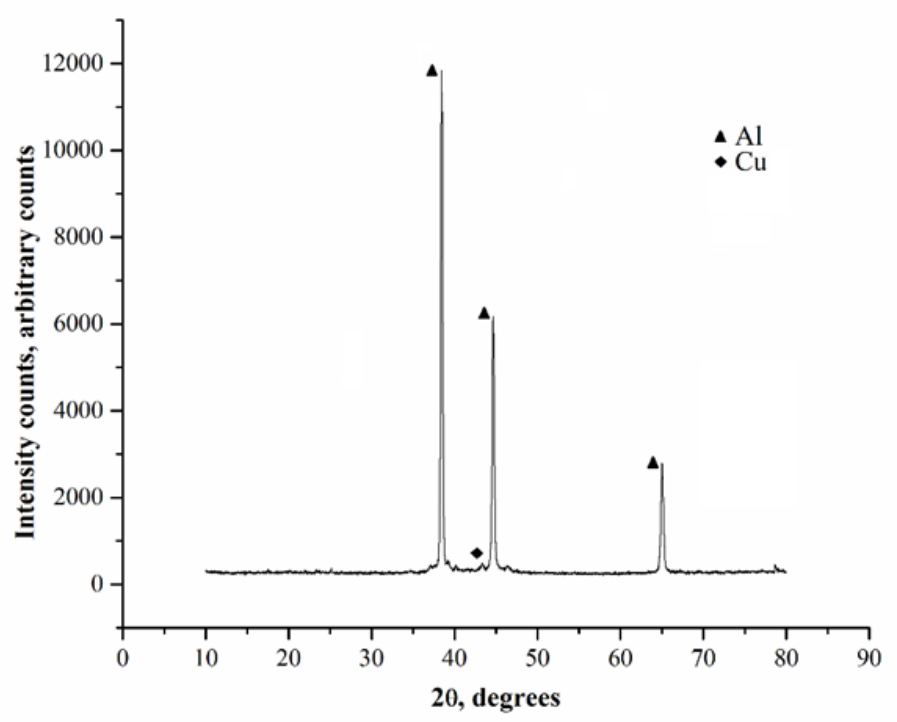

Figure.5: XRD of specimen A

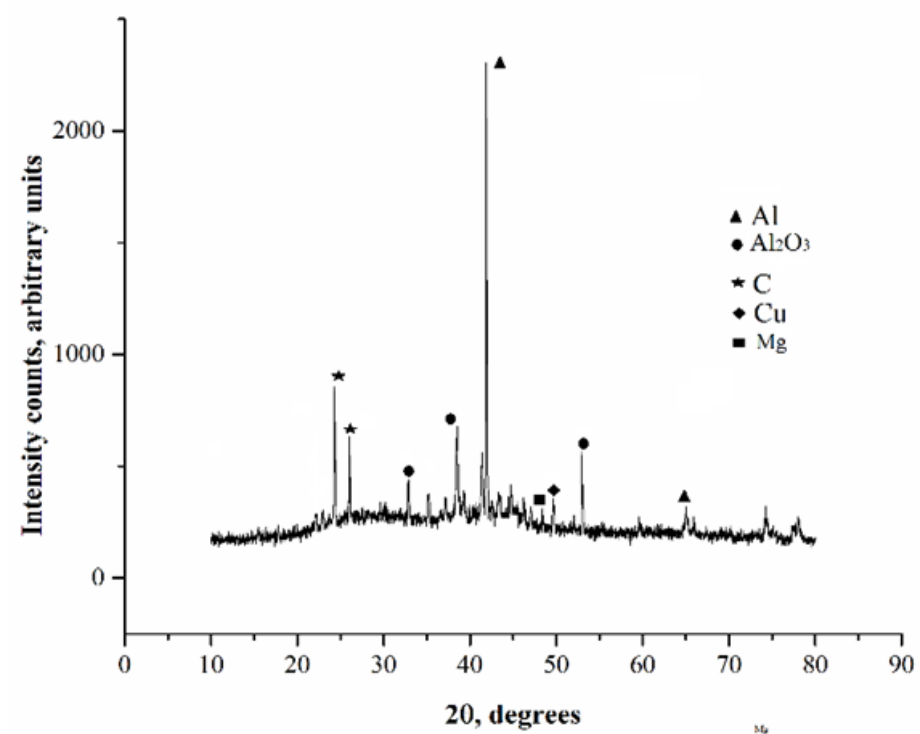

Figure.6: XRD of specimen $A_{1}$

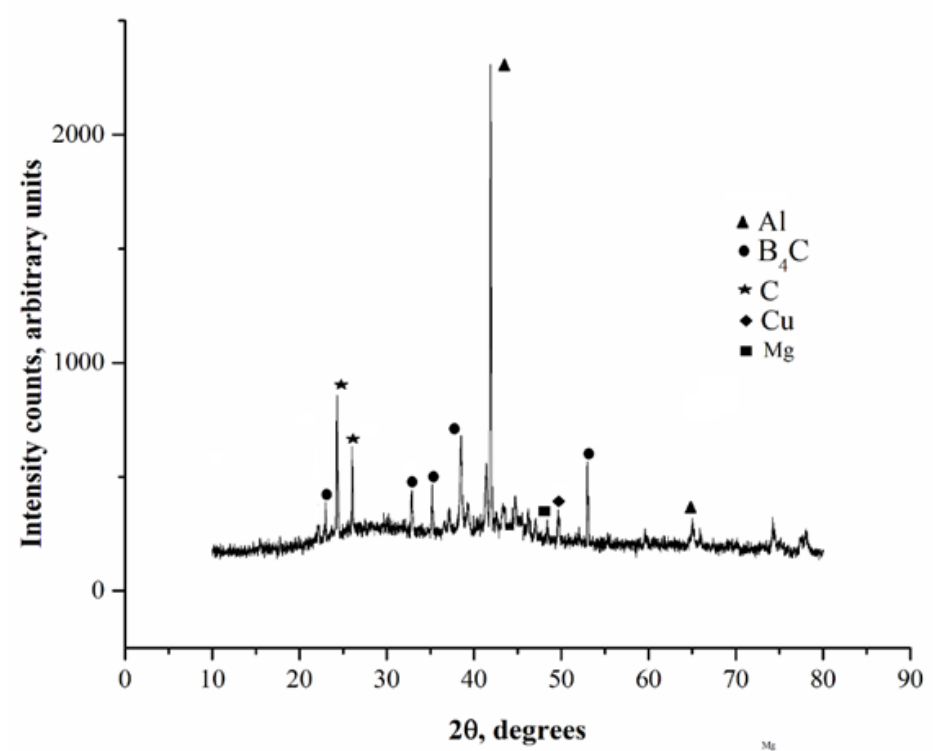

Figure. 7: XRD of specimen $\mathrm{A}_{2}$

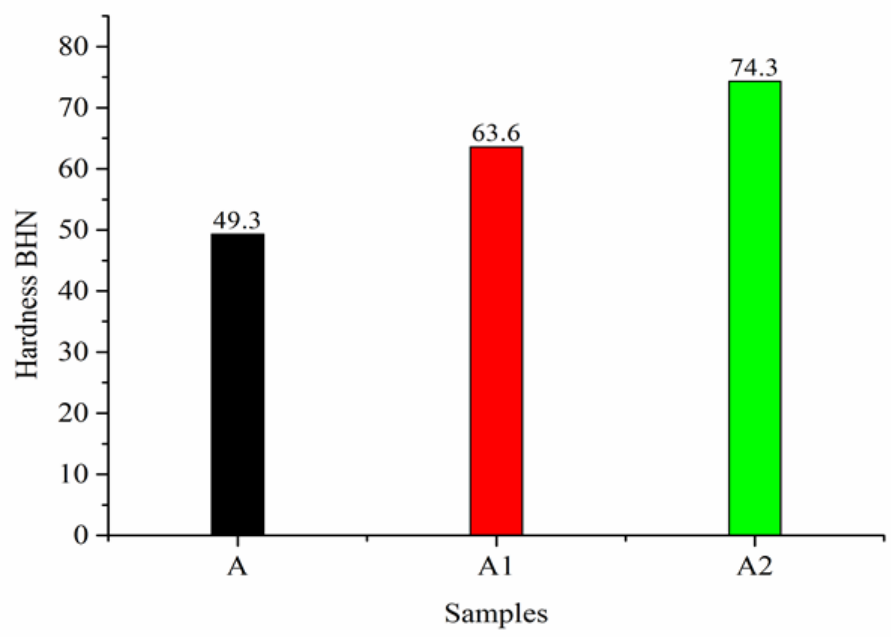

Figure.8: Hardness value

alloy surface became more damaged because of temperature. Due to synergetic action between $\mathrm{Al}_{2} \mathrm{O}_{3}$ and matrix, it exhibits more excellent wear resistance than unreinforced alloy, as shown in fig.9 [Wang et al. obtained similar observation]. Transition temperature between mild and severe wear not occurred. Thus wear resistance of the composite (A1) decreased monotonically at $150{ }^{\circ} \mathrm{C}$. Such variations can be seen in fig.12 [Mart'in et al. obtained similar observation].

The tests were done varying the normal load. At the atomic level, the surface of a material can not be entirely flat. When two surfaces are in contact, they touch each other at some points. When the load is applied, plastic deformation occurs locally in those points, which leads to the removal of material. More the load more will be the plastic deformation. Hence wear rate will be more at 40 N. Rate of plastic deformation will depend on applied load; therefore, less wear rate occurs at load $20 \mathrm{~N}$.

On the other hand, delamination was one of the most popular mechanisms which will drive the wear phenomenon, and the same can be seen from SEM images. When the two interacting surfaces slide against each other under load and heat, it can be observed, which results in the detachment of wear particles in the form of sheets or flakes. Moreover, ploughing action insists on taking plastic deformation and plastic flow at the asperities, as seen in SEM [similar result observed by Suresh et al.].

Graphite is acting as secondary reinforcement. It has a unique molecular structure consisting of a hexagonal carbon sheet held by strong hybridized carbon-carbon bonding; the motion of these sheets is easy to slip over each other, which results in excellent lubricating ability [4]. SEM observation results of the new alloy represented the ductile fracture mode with equi-axied crystals. Equi-axie crystals were mainly initiated by adding reinforcement due to uniform cooling. Due to the effect of $\mathrm{B}_{4} \mathrm{C}$ and Graphite, the rate of heat dissipation was reasonable; as a result, uniform crystals were formed. 


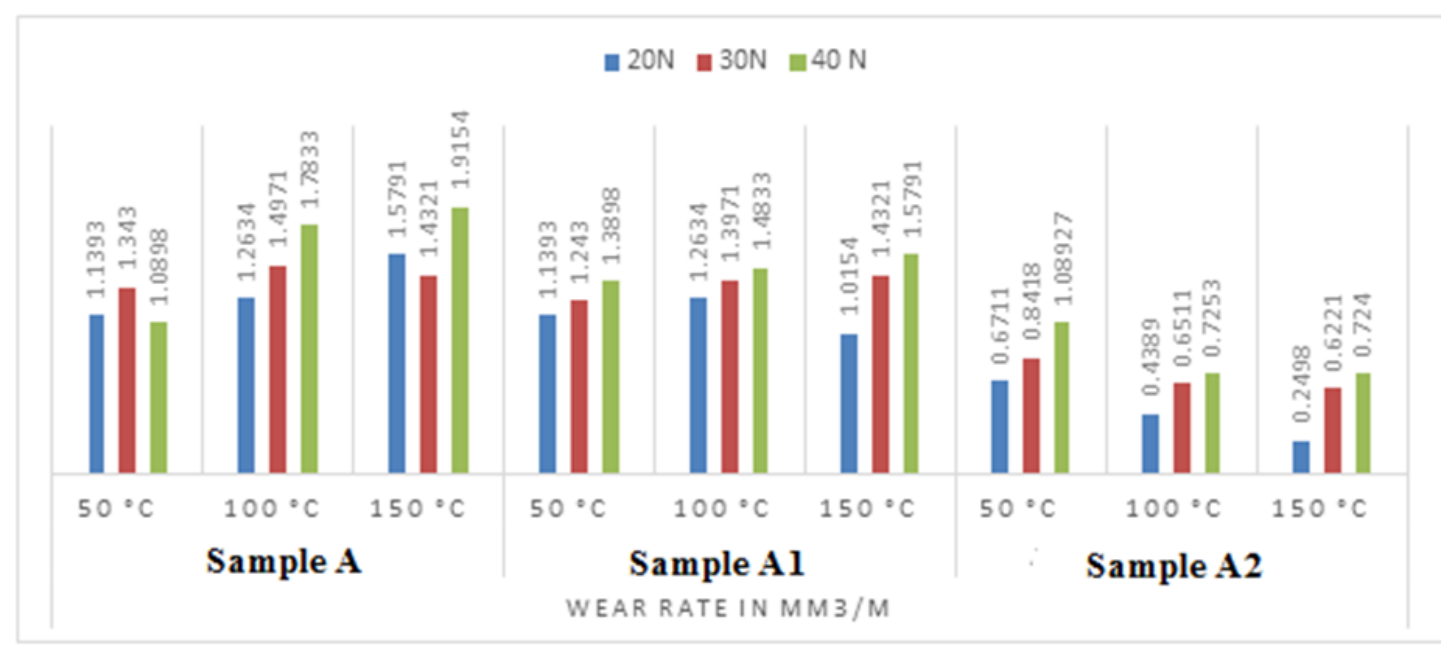

Figure.9 Load vs temperature

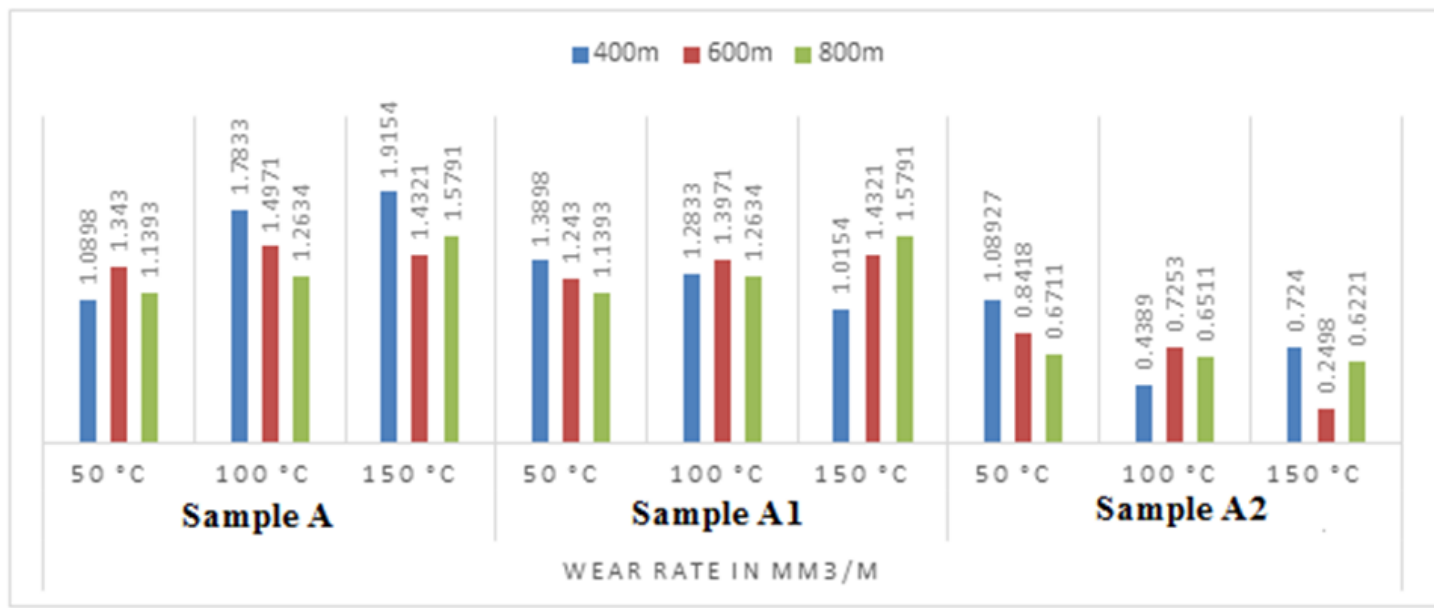

Figure.10 Temperature vs sliding distance

It was interposed that, though the AMMCs temperature was $150{ }^{\circ} \mathrm{C}$ still wear resistance of the composite could be maintained by reinforcement. Sample A2 possesses significantly improved wear resistance and hardness (74.3 $\mathrm{HN}$ ) contributed by the $5 \% \mathrm{~B}_{4} \mathrm{C}$ and $5 \%$ graphite reinforcement. However, these composites A2 are capable of performing at elevated temperatures substantially higher than $\mathrm{A}$ and $\mathrm{A} 1$. When $\mathrm{B}_{4} \mathrm{C}$ and graphite particulate as added into Al2219 tends to form layers that act as a preservative barrier which leads to creating an obstacle for dislocation. The dispersion-strengthening effect plays a significant role in improving wear resistance. Also, it is sustained at both ambient and high temperatures over prolonged periods [similar result observed by Biswas et al.]. According to current exploration, it clearly says that $\mathrm{B}_{4} \mathrm{C}$ and graphite content is an appropriate alternative to the conventional alloy to attain a higher wear resistance at $150{ }^{\circ} \mathrm{C}$. The existence of $\mathrm{B}_{4} \mathrm{C}$ and graphite particulate may improve the strengthening kinetics in the Matrix phase.

From the experimental findings (fig. 10) shows that. Wear resistance was improved due to the longer sliding distance. During high-temperature sliding, tearing of oxide layers occurs because of thermal stresses and compaction due to applied pressure resulting in agglomerated clusters of oxide wear debris. Eventually, due to temperature and applied pressure, sintering of fine wear debris occurs. The rate of sintering increases with the increase in temperature, resulting in solid smooth, hard surfaces, termed as tribolayer. The tribo layers protect the sliding surfaces for a longer time from developed forces, and hence the wear rate is reduced. The failure of tribo layer leads to the formation of the oxide layer and tearing of the oxide layer, resulting in sintering of the wear debris and the process getting repeated. It is evident from the wear trend that the tribo layer effect was not influenced at room temperature for alloy and composite.

So far, few studies noticed the effect of ceramics on Aluminium. In this contrast, $\mathrm{Al} 2219-\mathrm{B}_{4} \mathrm{C}$-graphite composites retain their high-temperature strength compared to the unreinforced matrix and $\mathrm{Al} 2219-\mathrm{Al}_{2} \mathrm{O}_{3}$-graphite. therefore, the possibility of further enhancement by increasing wt. \% of $\mathrm{B}_{4} \mathrm{C}$ and graphite particulates, and this segment additions is an attractive one and worth pursuing. 

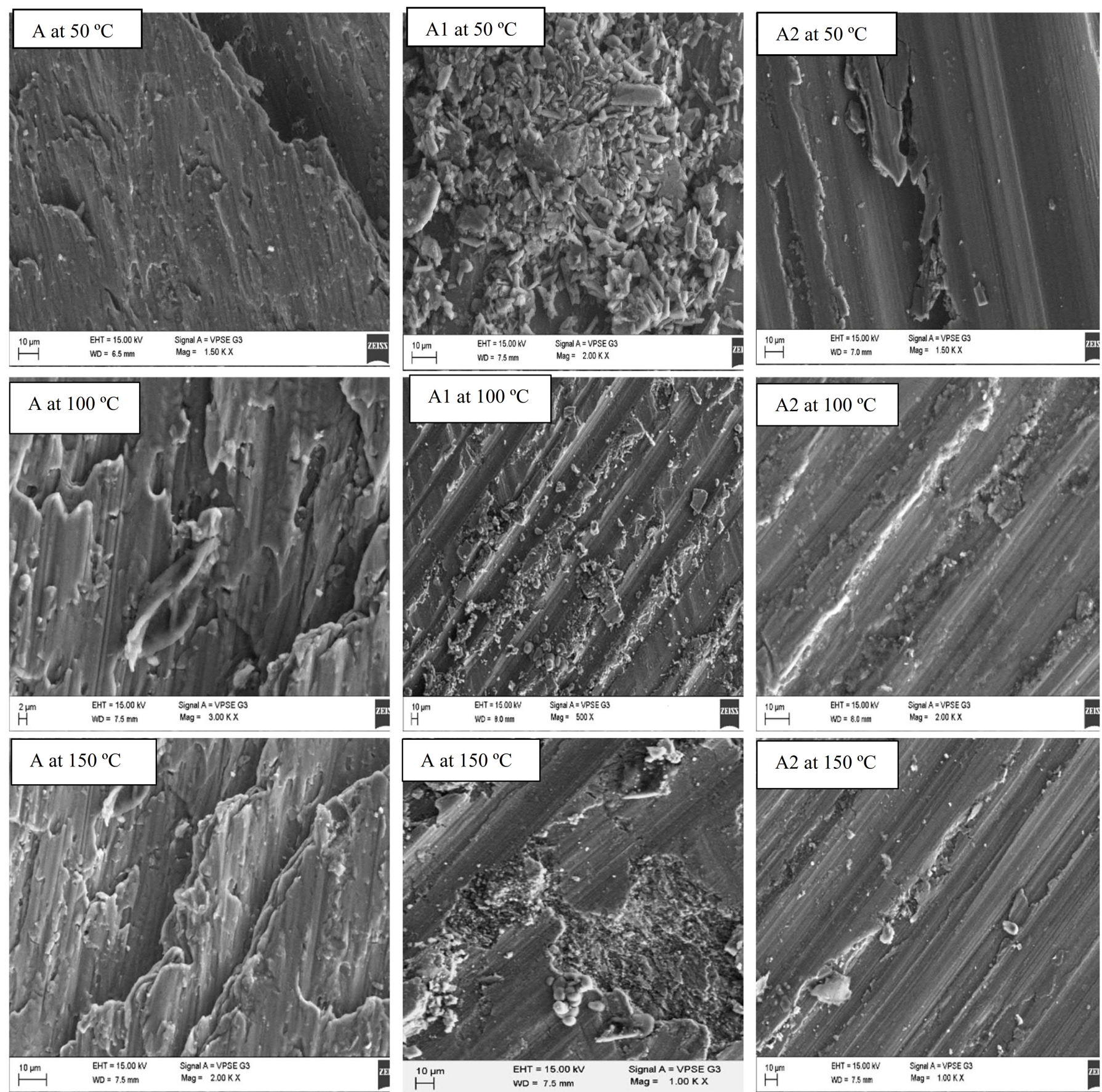

Figure.11 The worn surface of the test Pin at different temperature

\subsection{Artificial neural network}

IBM SPSS Statistics.22 was used to employ the ANN framework to predict the wear properties of the composite. An artificial neural network is an effective tool used to predict the wear properties of the alloy and AMMCs by the multilayer perceptron method. Five input vectors were used in constructing the proposed network (L: Load, S: Speed, D: Distance, T: Temperature, and W: Wear rate). Satisfactory effects can be calculated using the ANN outputs, thereby minimizing time and expense for research.

\subsubsection{ANN analysis for sample A:}

ANN was developed and deployed to aid a completely backpropagation neural network for this analysis (IBM SPSS Statistics 22). To activate the hidden layers (grey lines), the hyperbolic tangent function was chosen. The proposed ANN involves 27 trail, and the architecture of ANN is shown in fig.12.

An ANN consists of a large number of nodes (blue colour line) and their connections. Each node represents a specific output function termed an activation function.

The experimental values were correlated with expected ANN values to assess the efficiency of the validating pro- 


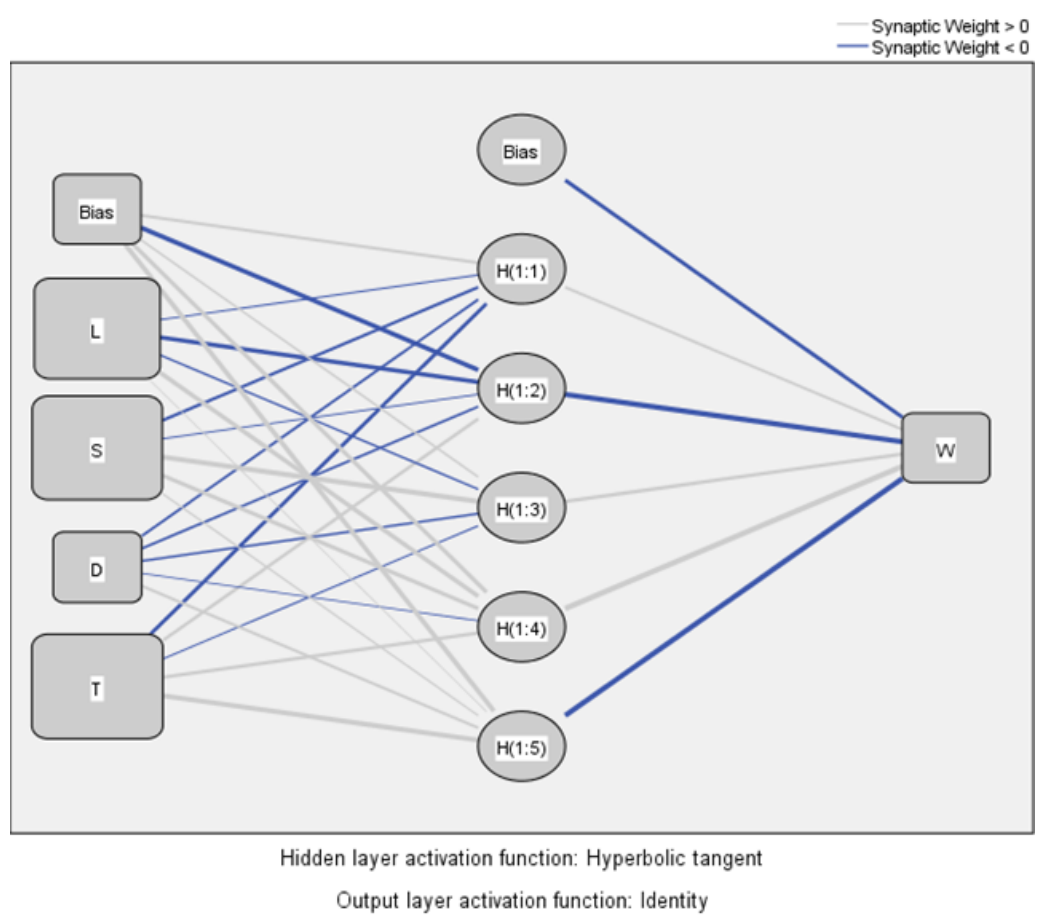

Figure.12 Architecture of ANN

Output layer activation function: Identity

cesses. It can be noted that the predictability of ANN output values significantly closer to experimental values. It is confirmed by seeing error graphs obtained by predicted values and experimental values, as seen in fig. 15 . The overall absolute relative error for the estimated value is less than $1 \%$. Fig. 14 confirms that temperature is a more imperative factor to attain maximum wear and followed by load and speed [similar result observed by Hassan et al.].

\subsubsection{ANN analysis for sample A1}

It is optimal when the ANN input data referred by testing condition. A well-trained ANN is beneficial to estimate the material characteristics. The experimental values were correlated with expected ANN values to assess the efficiency of the validating processes. It can be noted that ANN predictive outcomes fit actual measurement data, as seen in fig. 16. The overall absolute relative error for the estimated value is $0.4 \%$. Fig. 27 is confirmed that load is a more imperative factor to attain maximum wear and fallowed by speed and temperature.[ similar result observed by Zhang et al.]

\subsubsection{ANN analysis for sample A2}

A well-trained ANN has been used to measure the wear rate based on an experimental dataset for reinforced composites. The obtained result is significantly closer to measured data [Jiang et al. Observed similar result]. Prediction accuracy is also high, as seen in fig. 21 . The relative error is $0.2 \%$ only and confirms prediction quality as seen in fig.19. Normalized importance of factor is demonstrated load and speed are dominated by attaining higher wear rate in all the samples, as seen in the figure. 20.

\section{Conclusions}

In the present investigation, $\mathrm{Al} 2219, \mathrm{Al} 2219+\mathrm{Al}_{2} \mathrm{O}_{3}-$ graphite and $\mathrm{Al} 2219+\mathrm{B}_{4} \mathrm{C}$-graphite composites are fabricated using the stir casting technique. Experiments are performed based on the L27 orthogonal array. The following conclusions can be drawn.

- $\quad$ From the SEM analysis, it is concluded that the fabrication of the AMMCs liquid stir casting method is preferred because it yields in proper mixing of reinforcements with parent alloys.

- $\quad$ SEM and XRD confirm the distribution of $\mathrm{B}_{4} \mathrm{C}$ and graphite particles in the aluminium matrix.

- Increasing applied load and speed increases wear rate at all the temperature.

- Incorporating $\mathrm{B}_{4} \mathrm{C}$ and graphite particles helps the material to resist wear resulting in a lower wear rate.

- Tribo-layer of the AMMCs significantly influenced wear rate. The boron carbide and graphitereinforced AMMCs (A2) exhibits the lowest wear rate, while A12219 samples (A) shows the highest wear rate.

- It is also observed that abrasive and adhesive wear is a problem during sliding. This result indicated that $\mathrm{B}_{4} \mathrm{C}$ and graphite content is an appropriate alternative to conventional Al2219 metal matrix composites.

- Wear resistance of the hybrid composite A2 is dominant at $150{ }^{\circ} \mathrm{C}$ contrast with $\mathrm{A} 1$ and $\mathrm{A} 2$. Because of 


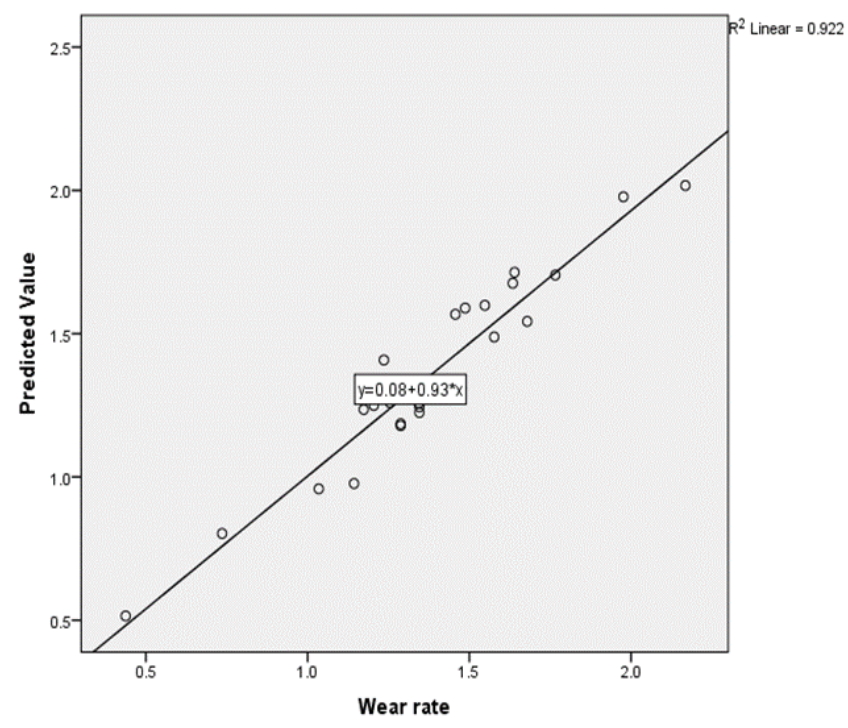

Figure. 13 Experimental vs predicted values.

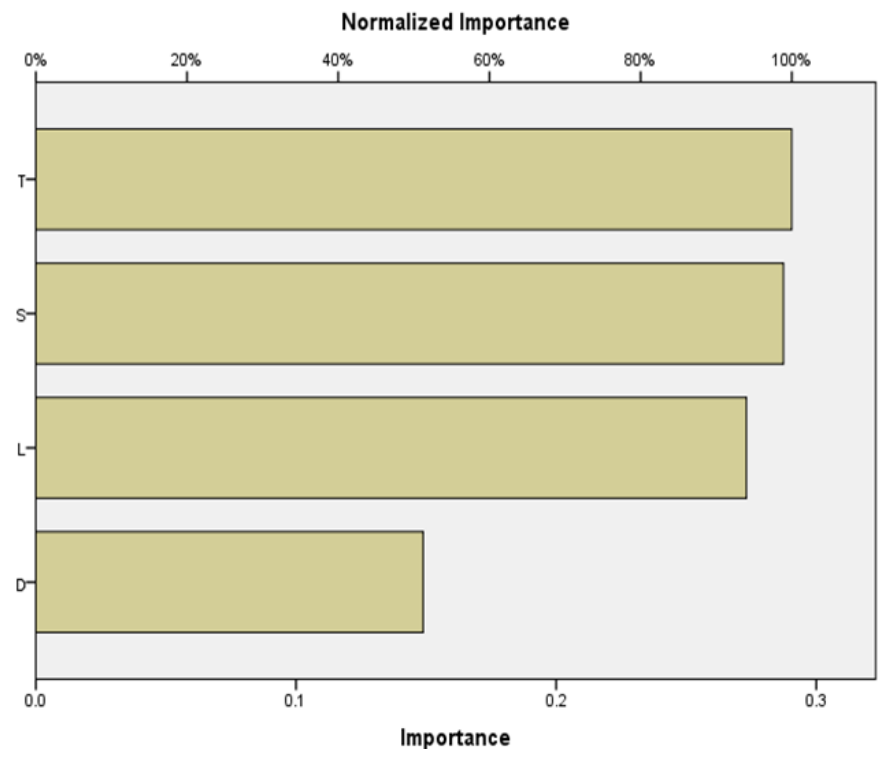

Figure.14 Normalized factor importance

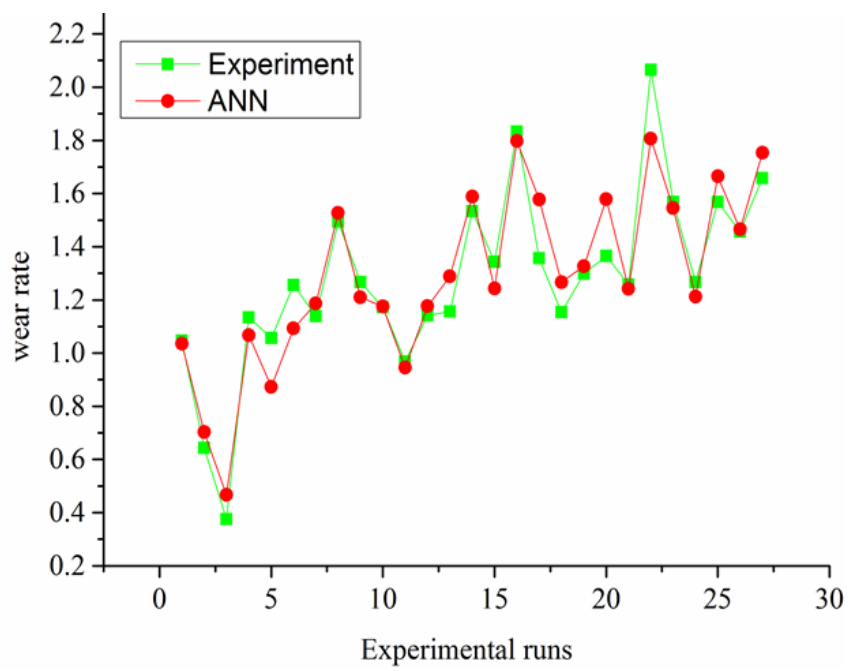

Figure.15 Error values.

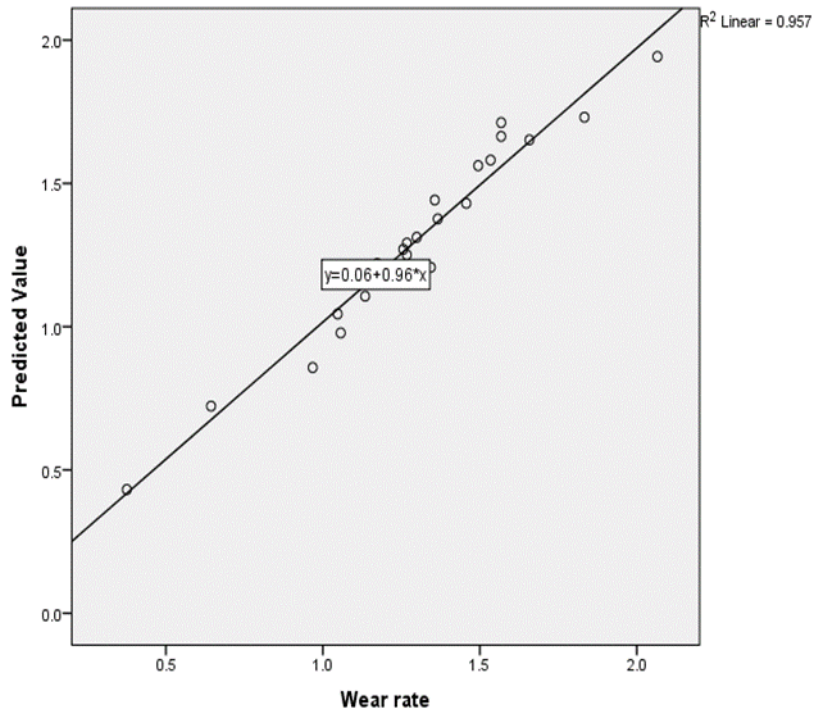

Figure.16: Experimental vs predicted values

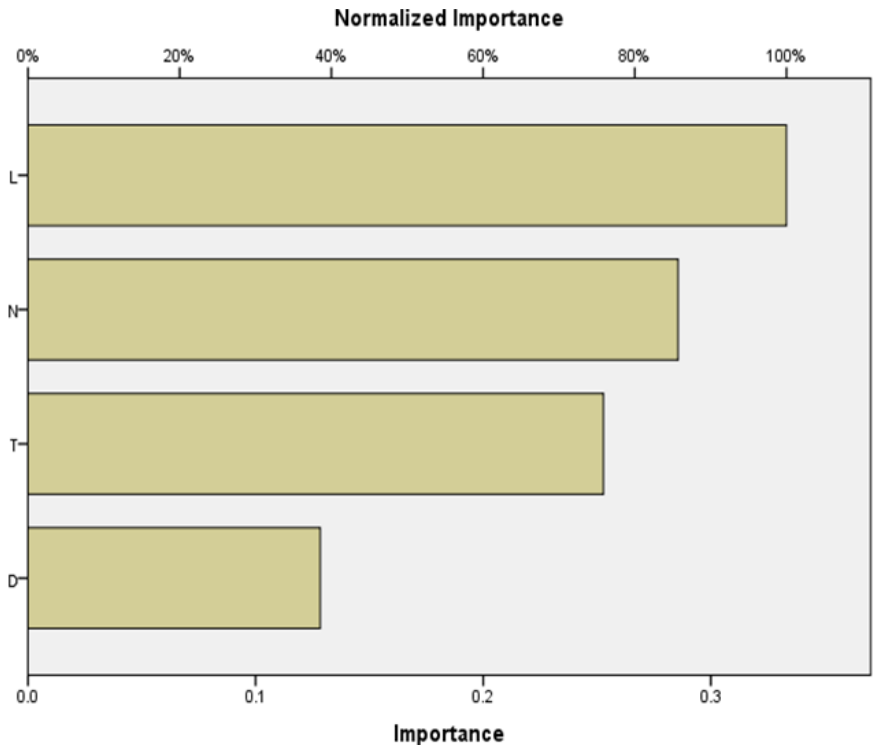

Figure.17: Normalized factor importance

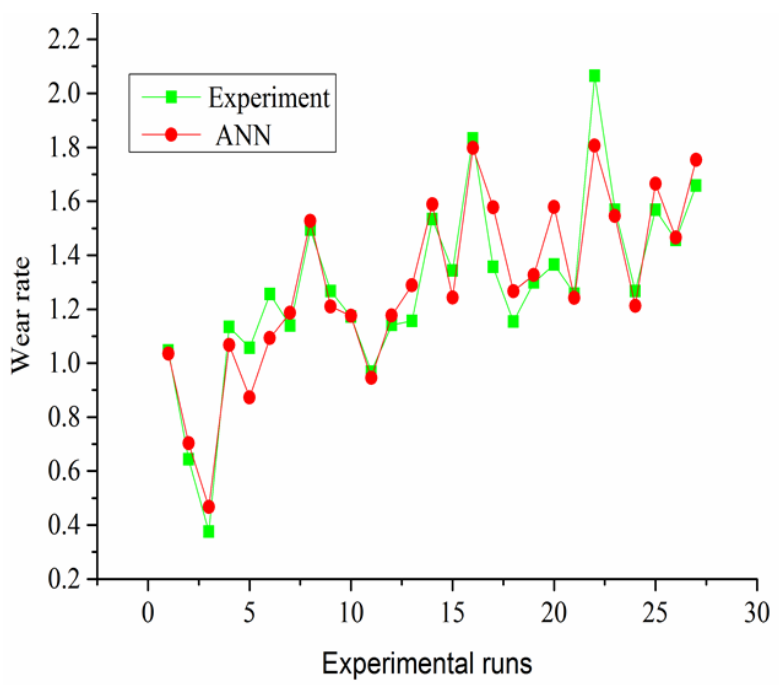

Figure.18: Error values 


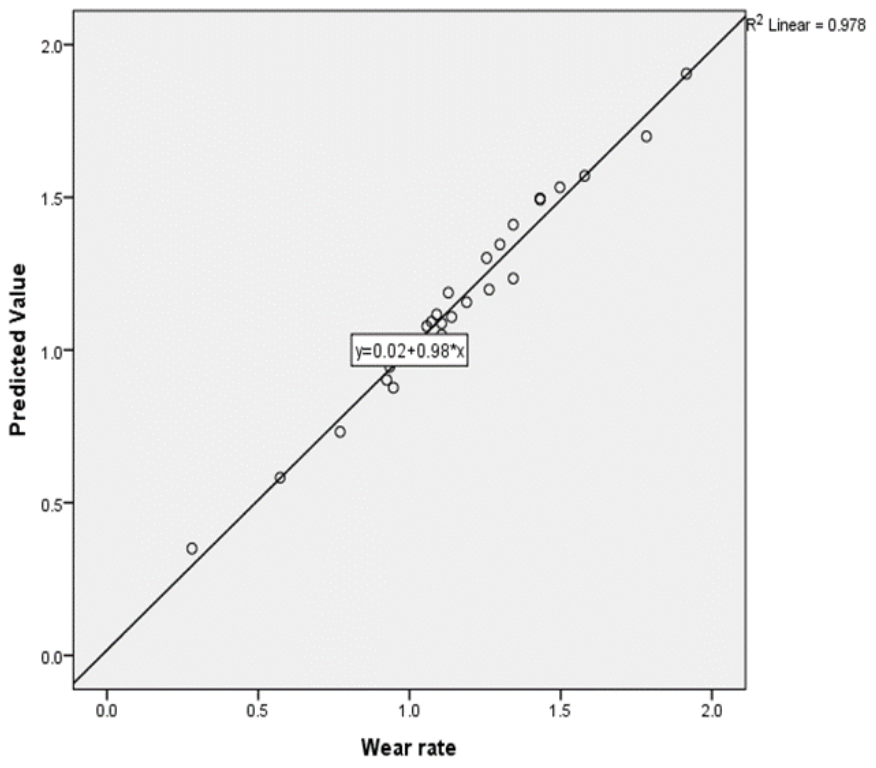

Figure.19 Experimental vs predicted values

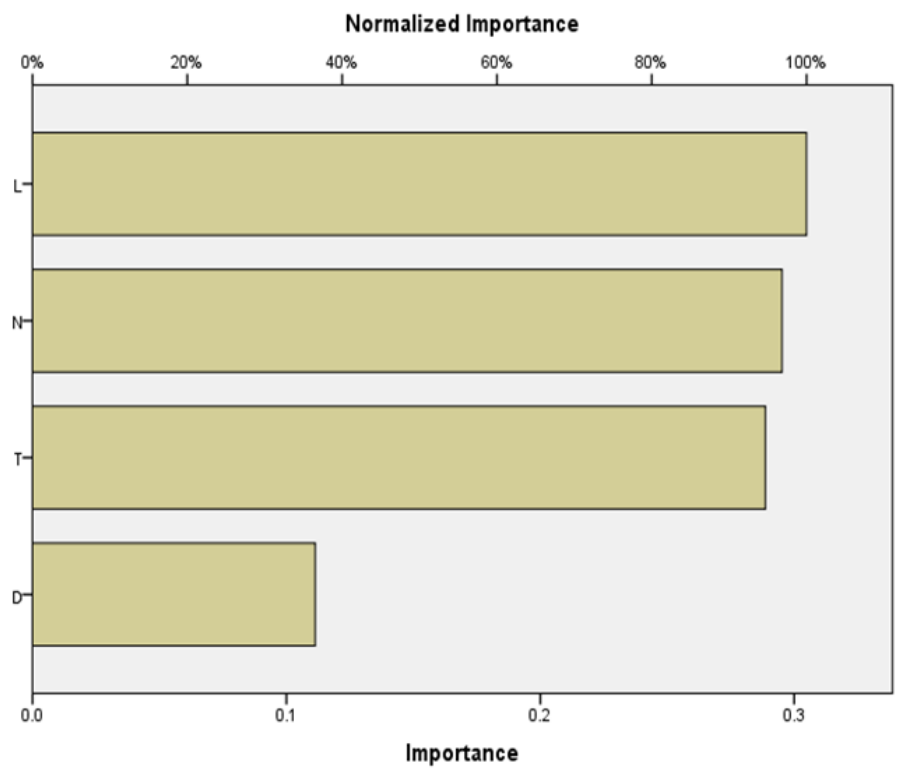

Figure.20 Normalized factor importance

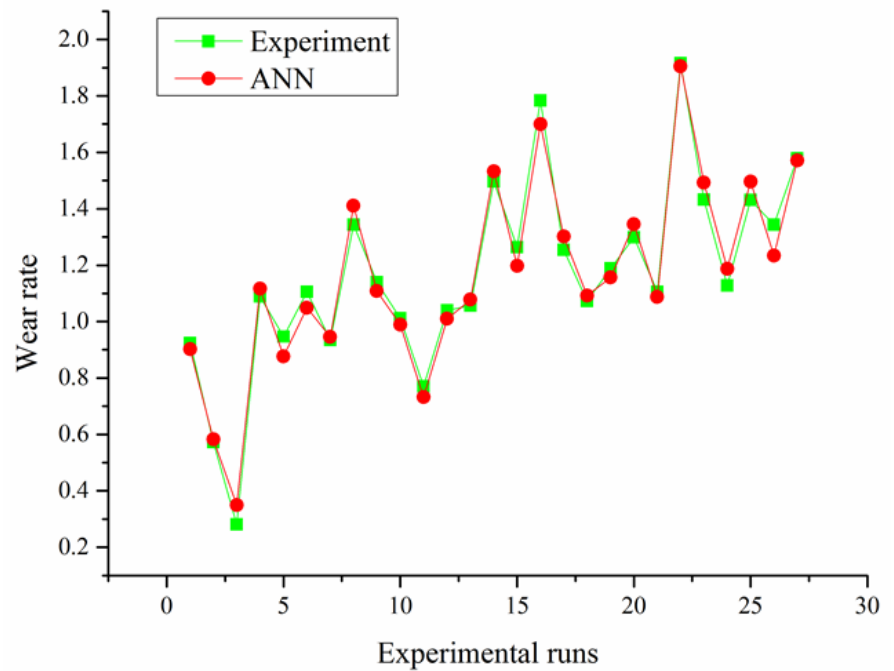

Figure.21 Error values the solid tribo layer formed by $\mathrm{B}_{4} \mathrm{C}$ and graphite, and detoration rate of tribo layer is meager. Thus boron carbide and graphite-reinforced AMMCs (A2) shows excellent wear resistance at all the temperature.

- $\quad$ ANN is a valuable statistical instrument for analyzing the wear properties of the AMMCs; the relative error predicted values fall within $1 \%$ compared with the experimental results.

- It can be noted that ANN predictive outcomes fit actual measurement data. It is confirmed that load is a more imperative factor to attain maximum wear and fallowed by speed and temperature.

\section{REFERENCES}

1 P.R.S. Kumar, S. Kumaran, T. Srinivasa Rao, S. Natarajan "High temperature sliding wear behavior of press-extruded AA6061/fly ash composite", Elsevier -Material Science and Engineering:A, Volume 527, Issue 6, Pages 1501-1509, 2010. https:// doi.org/10.1016/j.msea.2009.10.016

2 Ham, A.L., Yeomans, J.A. and Watts, J.F. Effect of temperature and particle velocity on the erosion of a silicon carbide continuous fibre reinforced calcium aluminosilicate glass-ceramic matrix composite. Wear, 233, pp.237-245. 1999 https:// doi.org/10.1016/S0043-1648(99)00222-7

3.A Abou Gharam,M.J. Lukitsch,.High temperature tribological behaviour of carbon based(B4C and DLC) coating in sliding contact with aluminum", ElsevierThin Solid Films,Volume 519, Issue 5, Pages 16111617,30.2010. https:// doi.org/10.1016/ j.tsf.2010.07.074

4 Suresha, S. and Sridhara, B.K. Effect of silicon carbide particulates on wear resistance of graphitic aluminium matrix composites. Materials and Design, 31(9), pp.4470-4477. 2010 https://doi.org/10.1016/ j.matdes.2010.04.053

5 S.M.R. Mousavi Abarghouie, S.M. Seyed Reihani "Investigation of friction and wear behaviors of 2024 $\mathrm{Al}$ and $2024 \mathrm{Al} / \mathrm{SiCp}$ Composite at elevated temperatures", Elsevier-Journal of Alloys and compounds,Volume 501, Issue 2, Pages 326-332. 2010. https:// doi.org/10.1016/j.jallcom.2010.04.097

6 Onoro, J., Salvador, M.D. and Cambronero, L.E.G. Hightemperature mechanical properties of aluminium alloys reinforced with boron carbide particles. Materials Science and Engineering: A, 499(1-2), pp.421426. 2009. https:// doi.org/10.1016/ j.msea.2008.09.013

7 Rana, R.S., Purohit, R. and Das, S. Reviews on the influences of alloying elements on the microstructure and mechanical properties of aluminum alloys and aluminum alloy composites. International Journal of 
Scientific and research publications, 2(6), pp.1-7. 2012

8.Gómez-del Río, T., Rico, A., Garrido, M.A., Poza, P. and Rodríguez, J.Temperature and velocity transitions in dry sliding wear of Al-Li/SiC composites. Wear, 268 (5-6), pp.700-707. 2010. https://doi.org/10.1016/ j.wear.2009.11.006

9.A. Mart'in, J. Rodr'iguez , J. Llorca “Temperature effects on the wear behaviour of particulate reinforced Albased composites", ElsevierVolumes 225-229, Part 1, Pages 615-620.1999. https:// doi.org/10.1016/S0043$\underline{1648(98) 00385-8}$

10 LLorca, J. High temperature fatigue of discontinuously -reinforced metal-matrix composites. International journal of fatigue, 24(2-4), pp.233-240.2002. https:// doi.org/10.1016/S0142-1123(01)00077-9

11 Suresha, S. and Sridhara, B.K. Wear characteristics of hybrid aluminium matrix composites reinforced with graphite and silicon carbide particulates. Composites Science and Technology, 70(11), pp.16521659.2010. https:// doi.org/10.1016/ j.compscitech.2010.06.013

12.Radhika, N., Subramanian, R. and Prasat, S.V. Tribological behaviour of aluminium/alumina/graphite hybrid metal matrix composite using Taguchi's techniques. Journal of Minerals and Materials Characterization and Engineering, 10(05), p.427. 2010. https:// doi.org/10.4236/jmmce.2011.105032

13 Kumar, A., Lal, S. and Kumar, S. Fabrication and characterization of A359/A12O3 metal matrix composite using electromagnetic stir casting method. Journal of Materials Research and Technology, 2(3), pp.250254.2013 https:// doi.org/10.1016/ij.jmrt.2013.03.015

14 Auradi, V., Rajesh, G.L. and Kori, S.A. Processing of B4C Particulate Reinforced 6061Aluminum Matrix Composites by melt stirring involving two-step addition. Procedia Materials Science, 6, pp.1068-1076. 2014. https:// doi.org/10.1016/j.mspro.2014.07.177

15 Ahmed, A., Wahab, M.S., Raus, A.A., Kamarudin, K., Bakhsh, Q. and Ali, D. Mechanical properties, material and design of the automobile piston: an ample review. Indian Journal of Science and Technology, 9 (36). 2016. https://doi.org/10.17485/ijst/2016/ v9i36/102155

16 G. Rajaram, S. Kumaran, T. Srinivasa Rao “High temperature tensile and wear behavior of aluminum silicon alloy", Elsevier Material Science and Engineering:A, Vol 528, issue1, Pages 247-253, 25 November 2010. https://doi.org/10.1016/ j.msea.2010.09.020

17.S.G. Shabestari, H. Moemeni Effect of copper and solidification conditions on the microstructure and mechanical properties of Al-Si-Mg alloys Journal of
Materials Processing Technology 153-154,193198.2004. https:// doi.org/10.1016/ j.jmatprotec.2004.04.302

18 Davis, J. R., Corrosion of Aluminum and Aluminum alloys, Ohio,ASM International.1999. https:// doi.org/10.31399/asm.tb.caaa.9781627082990

19 Mondolfo, L. F., Aluminum alloys: Structure and Properties, London, Butterworths. 1999.

20 Gul, F. and Acilar, M. Effect of the reinforcement volume fraction on the dry sliding wear behaviour of $\mathrm{Al}$ -10Si/SiCp composites produced by vacuum infiltration technique. Composites Science and Technology, 64(13-14), pp.1959-1970.2004. https:// doi.org/10.1016/j.compscitech.2004.02.013

21 Sharath, B.N., Madhu, K.S. and Venkatesh, C.V. Experimental Study on Dry Sliding Wear Behaviour of AlB4C-Gr Metal Matrix Composite at Different Temperatures. J. Applied Mechanics and Materials, 895, pp. 96-101. 2019. https://doi.org/10.4028/ www.scientific.net/AMM.895.96

22 Czichos, H., Becker, S., and Lexow, J., Wear, Vol 114, pp 109-130.1987. https:// doi.org/10.1016/0043-1648 (87)90020-2

23 Manual on Quality Control of Materials, ASTM STP 15D, ASTM, 1951.

24.Singh, G. and Goyal, S. Microstructure and mechanical behavior of AA6082-T6/SiC/B4C-based aluminum hybrid composites. Particulate Science and Technology, 36(2), pp.154-161.2014. https:// doi.org/10.1080/02726351.2016.1227410

25 ASTM Standards2

26.Y.Q. Wang, J.I. Song “Temperature effects on the dry sliding wear of Al2O3f/SiCp/Al MMCs withdifferent fiber orientations and hybrid ratios", ElsevierWear,Volume 270, Issues 7-8, Pages 499-505,10.2011. https://doi.org/10.1016/j.wear.2011.01.002

27.Abdizadeh, H. and Baharvandi, H.R. Development of high-performance A356/nano-Al2O3 composites Mater. Sci. Eng. A, 518, pp.61-64.2009. https:// doi.org/10.1016/j.msea.2009.04.014

28 Kaibyshev, R., Sitdikov, O., Mazurina, I. and Lesuer, D.R. Deformation behavior of a $2219 \mathrm{Al}$ alloy. Materials Science and Engineering: A, 334(1-2), pp.104113.2002. https://doi.org/10.1016/S0921-5093(01) $\underline{01777-4}$

29 Biswas, S., Dwarakadasa, E. and Biswas, S. K. "Bearings and wear properties of cast graphite aluminium composites", Proceedings of All India Seminar on Aluminium, pp 189-196.1979.

30 G. Straffelini, M. Pellizzari, A. Molinari “Influence of load and temperature on the dry sliding behaviour of Al-based metal-matrix-composites against friction 
material",Elsevier-Wear,Volume 256, Issues 7-8, Pages 754-763,2004. https:// doi.org/10.1016/S0043-1648 (03)00529-5

31 Heguo Zhu a,n, CuicuiJar a, JinzhuSong a, JunZhao a, JianliangLi a, ZonghanXie b,nn "Microstructure and high temperature wear of the aluminium matrix composites fabricated by reaction technique from AlZro2-B elemental powder",Elsevier-Powder Technology,Volume 217, Pages 401-408.2012. https:// doi.org/10.1016/j.powtec.2011.10.056

32 Heguo Zhu a, n, CuicuiJar a, JinzhuSong a, JunZhao a, JianliangLi a, ZonghanXie b, nn "High temperature dry sliding friction and wear characteristics of in situ composites (a-Al2O3pAl3Zr)/ Al" , Advanced Materials Research, Vols. 690-693, pp. 318-322, 2013.

https://doi.org/10.4028/www.scientific.net/ AMR.690-693.318

33 Hassan, A.M., Alrashdan, A., Hayajneh, M.T. and Mayyas, A.T. Prediction of density, porosity and hardness in aluminum-copper-based composite materials using artificial neural network. Journal of materials processing technology, 209(2), pp.894899.2009. https://doi.org/10.1016/ j.jmatprotec.2008.02.066

34 Zhang, Z., Barkoula, N.M., Karger-Kocsis, J. and Friedrich, K. Artificial neural network predictions on erosive wear of polymers. Wear, 255(1-6), pp.708713.2003. https://doi.org/10.1016/S0043-1648(03) 00149-2

35 Jiang, Z., Zhang, Z. and Friedrich, K. Prediction on wear properties of polymer composites with artificial neural networks. Composites Science and Technology, 67(2), pp.168-176.2007. https:// doi.org/10.1016/j.compscitech.2006.07.026 